Non-pharmacological interventions for post-stroke emotionalism (PSE)

within inpatient stroke settings: A Theory of Planned Behavior survey

Corresponding author:

David C Gillespie

Clinical Neuropsychology Service

Department of Clinical Neurosciences (DCN)

Western General Hospital

Edinburgh UK

Email : david.gillespie@nhslothian.scot.nhs.uk

Amy P Cadden

Neuropsychology Service

Great Ormond Street Hospital for Children

London UK

Robert M West

Institute of Health Sciences

University of Leeds

Leeds UK

Niall M Broomfield

The Medical School

University of East Anglia

Norwich UK

Word Count: 4481 (excluding references)

Keywords

emotionalism, stroke, rehabilitation, interventions, survey 


\title{
Non-pharmacological interventions for post-stroke emotionalism (PSE) within inpatient stroke settings: A Theory of Planned Behavior survey
}

\begin{abstract}
Background: Post-stroke emotionalism (PSE) is common. Trials of antidepressants for PSE suggest only modest clinical benefit and risk of side effects. There have been no trials of non-pharmacological treatments for PSE; in fact, little is known about the non-pharmacological treatments actually provided to PSE sufferers in clinical practice.
\end{abstract}

Objectives: To determine the non-pharmacological interventions provided by stroke professionals, their perceived effectiveness, and the factors associated with the intention to provide them.

Methods: Focus groups and published sources of information were used to construct a comprehensive list of non-pharmacological approaches for PSE. This was followed by a national (online) survey of 220 UK stroke clinicians from nursing, medicine and the allied health professions to investigate the approaches used in clinical practice, using Theory of Planned Behavior components to determine the factors associated with intention to provide them.

Results: Most respondents reported high intention to provide non-pharmacological interventions from the list that was constructed. Offering reassurance and talking to patients about goals were the commonest interventions, and distraction and tensing facial muscles least common. Respondents who perceived others to hold them 
professionally responsible for carrying out non-pharmacological approaches were more likely to use them, as were respondents who held more positive attitudes.

Conclusions: Our survey data reveal that stroke clinicians report regular use of nonpharmacological interventions for PSE. There is a pressing need for well-conducted clinical trials to evaluate the effectiveness of these approaches. 


\section{Introduction}

Post-stroke emotionalism (PSE) refers to a lessening of control over emotions such that individuals find themselves crying uncontrollably at something that is only moderately sad, or laughing uncontrollably when a situation is not objectively humorous. ${ }^{1}$ There are reports of emotionalism following multiple sclerosis, ${ }^{2}$ Parkinson's disease, ${ }^{3}$ and amyotrophic lateral sclerosis, ${ }^{4}$ but the condition is most prevalent following stroke..$^{5,6}$

The pathophysiological mechanisms underlying PSE have been the subject of much speculation. Several studies have implicated cortico-pontine-cerebellar circuit damage in the onset of the condition, specifically disruption to the cerebellum's role in modulating emotional responses and aligning them to fit contextual information from the cortex. ${ }^{7,8}$ Disruption to pathways involving serotonin and glutamate have also been implicated, but these mechanisms are incompletely understood. ${ }^{9}$ Fewer studies have investigated the psychological mechanisms involved in the onset or maintenance of PSE. In one investigation, the association of irritability with PSE suggested possible links with post traumatic stress disorder, because both conditions involve the experience of recurring uncontrollable emotionally charged events. ${ }^{10}$ To the current authors' knowledge, there have been no replications, or extensions of this work. A more recent investigation has suggested that PSE sufferers' beliefs and attitudes play a role in the maintenance of the condition. ${ }^{11}$ Individuals reported feeling guilty about the impact of their PSE symptoms on others, with overly sympathetic responses from people around them appearing to exacerbate the very emotional reaction that evoked the sympathy in the first place. 
Indeed, PSE can have a significant impact on social functioning and relationships. Many sufferers avoid social interaction because of embarrassment, and have lower quality of social contact. ${ }^{12}$ In the qualitative investigation referred to above, ${ }^{11}$ PSE sufferers engaged in avoidance (e.g. of certain topics in conversation) and safety behaviors (e.g. always being with a family member). The authors hypothesise that avoiding social contact is likely to maintain a person's anxiety by preventing habituation to the social and cognitive consequences of the condition.

Although the majority of stroke survivors with PSE have normal mood, ${ }^{10}$ several studies have shown that depression is more likely in individuals with PSE. ${ }^{1,8,13}$ Although depression and PSE may share some common pathophysiological mechanisms, for example disruption to serotonergic transmitter pathways, ${ }^{14}$ the evidence suggests that they are distinct conditions. The crying of individuals with PSE is usually brief and subjectively uncontrollable and occurs in the absence of depressogenic beliefs. In individuals with depression, crying may be prolonged and occurs alongside thoughts about hopelessness and low self-worth. ${ }^{8}$ Uncontrollable laughter is a feature of PSE, but not depression. ${ }^{14}$

The prevalence of PSE is high. A recent systematic review and meta-analysis of published studies indicated that the crying component affects approximately $20 \%$ of stroke survivors at the acute/post-acute recovery phase, and approximately $12 \%$ at six months post-stroke and beyond. ${ }^{6}$ Little is known about how common the laughter component is; ${ }^{6,15}$ there is a pressing need for well-designed longitudinal 
studies. Another gap in the literature concerns treatment. Relatively little is known about the best ways to treat or manage PSE.

The available evidence suggests that medication can be effective. Antidepressant medication was shown to reduce frequency of uncontrolled crying in a Cochrane review. ${ }^{5}$ The clinical benefits however are, at best, modest, and side effects are experienced in a significant proportion of patients who take them. It is for this reason that clinicians are advised to exercise caution when prescribing. ${ }^{16}$ Of course, some people may not wish to take medication, or may simply prefer nonpharmacological to pharmacological treatments. The former involve individuals learning ways to cope with PSE, and align well with self-management approaches for long-term conditions like stroke. ${ }^{17}$ Unfortunately, the same Cochrane review ${ }^{5}$ found no published randomized or quasi-experimental studies of non-pharmacological treatments for PSE, and only one clinical case series involving four stroke patients with locked-in syndrome. ${ }^{18}$ In this work - an extension of an uncontrolled single case series presented four years earlier ${ }^{19}$ - individuals were taught how to impose voluntary control on facio-respiratory muscles in order to strengthen the prefrontal areas involved in the inhibition of emotional reflexes. Desensitization to increasingly stressful triggers was then implemented. The results of both studies were promising, with most individuals, even those with longstanding PSE, experiencing reduction in the duration of labile episodes. More recently, a self-control procedure involving the anticipation of cues for crying and the use of breathing techniques at symptom onset was found to reduce PSE symptoms. ${ }^{20}$ The results of these studies are, however, preliminary and await replication in controlled trials. No controlled investigations of 
cognitive behavioral therapy (CBT) for PSE have been carried out, even though CBT has been shown to be effective in the treatment of other emotional difficulties following stroke. ${ }^{21}$ It is surprising that this work has not been undertaken, because the erroneous and unhelpful beliefs and the avoidance and safety behaviors found in many individuals with $\mathrm{PSE}^{11}$ would be ideal targets for traditional CBT, or newer 'third wave' behavioral therapies such as Acceptance and Commitment Therapy $(\mathrm{ACT}) .{ }^{22}$

In actual fact, there is a dearth of information about what clinicians do provide in terms of non-pharmacological treatment, how often they provide such treatments, and how helpful they believe them to be. A qualitative study involving interviews with stroke clinicians from a variety of disciplines, ${ }^{23}$ highlighted these uncertainties. Clinician confidence in how to respond to PSE was found to be generally low, and this was true even for clinicians with many years experience in stroke care. Interviewees felt a strong desire to be helpful to individuals who experience PSE, but were unsure about which non-pharmacological treatments should be provided and who should provide them, particularly when PSE occurred in the context of other stroke related changes such as depression, behavioral changes, unawareness of deficit and language difficulties.

In the absence of good quality evidence from clinical trials, and when uncertainties exist about how best to respond to PSE, we suppose that individual clinician decisions might be central to the adoption of particular ways of managing PSE. Our understanding of how these decisions are made is incomplete. Which factors 
influence individuals' decisions to provide non-pharmacological interventions for PSE? One model that has been used to examine the influence of social cognitive variables on the prediction of clinician behavior is the Theory of Planned Behavior (TPB). ${ }^{24}$

Theory of Planned Behavior

The TPB, developed by the social psychologist Icek Ajzen, ${ }^{24}$ provides a conceptual framework to explain the influence of attitudes and beliefs on variation in behavior. The TPB states that the main determinant of a behavior is the individual's intention to perform it. In turn, the strength of that intention is determined by three variables, namely attitudes towards the behavior, subjective norms and perceived behavioral control. Attitudes towards the behavior concern a person's evaluations of the behavior, and are assumed to have two components, beliefs about the consequences of the behavior (e.g. 'distracting a patient when PSE appears will allow them to carry on an activity') and corresponding positive or negative outcome evaluations (e.g. 'being able to carry on with an activity is a desirable/undesirable thing'). Subjective norms are a person's estimate of the social pressure to perform (or not perform) the target behavior, and are made up of two components, beliefs about how other people would like or expect them to behave (e.g. 'my colleagues expect me to act when someone displays PSE') and the positive or negative outcome evaluations about each belief (e.g. 'doing what my colleagues think I should do is important/unimportant'). Perceived behavioral control is the extent to which a person feels able to carry out the behavior. It also has two components, namely how much control a person feels they have over the behavior (e.g. low control if they 
have too little time to provide non-pharmacological interventions for PSE) and how confident they feel about being able to perform it (e.g. sufficiently or insufficiently skilled at being able to teach a skill or technique).

Although the TPB has been used most often to investigate the behavior of patients or healthy populations (e.g. in relation to smoking, alcohol consumption, the take up of screening opportunities), ${ }^{25}$ the framework has been also used to predict clinician behavior, for example in relation to blood pressure monitoring, ${ }^{26}$ and bowel management practice. ${ }^{27}$ In stroke care, the model has been used to predict oral hygiene care provision ${ }^{28}$ and the intention to screen for depression. ${ }^{29}$ Intention has been shown to be a valid proxy measure for behavior in healthcare workers. ${ }^{30} \mathrm{~A}$ diagrammatic representation of the TPB is shown in Figure 1.

INSERT FIGURE 1 HERE

The aims of this study were to determine (a) the types of non-pharmacological interventions for PSE employed by professionals working in inpatient stroke settings; (b) how effective these interventions are perceived to be; and (c) the factors associated with intention to use them.

\section{Methods}

Determining a List of Non-Pharmacological PSE Interventions 
We consulted the following four data sources: (a) published, national English language stroke clinical guidelines from the USA, UK, Australia, New Zealand, Canada and the Netherlands; (b) the five best selling stroke psychological and rehabilitation medicine textbooks at the time of the evaluation on Amazon UK (www.amazon.co.uk) $)^{31-35}$ and a stroke psychology textbook; ${ }^{36}$ (c) the 'Stroke Training And Awareness Resources', an on-line training platform for stroke; ${ }^{37}$ and (d) transcribed data arising from two separate researcher-led focus groups held in each of two UK Health Boards (HBs), together comprising nine stroke professionals (nursing $=4$, medicine $=2$, occupational therapy $=1$, physiotherapy $=1$, social work=1). We did not search peer reviewed papers from electronic databases, because the published stroke guidelines we consulted had all used systematic literature searching, and we did not deem it necessary to repeat this process.

\section{Survey Design and Construction}

We constructed a standardized survey questionnaire containing the nonpharmacology PSE intervention approaches. Clinicians responded to two key questions: (i) 'How often over the past 12 months have you provided [this] non- drug intervention approach?' (rated from 1= never, to 7 = very often), and (ii) 'Where you gave a rating of 2 or more (i.e. you have provided the intervention in question), rate how effective you have personally found [this] approach' (rated from $1=$ not effective, to 7 = very effective).

The second section of the survey questionnaire comprised items designed to capture TPB components. We used a published manual to construct our TPB questionnaire. ${ }^{25}$ 
A seven-point scale was used to determine how likely respondents were to provide a non-pharmacological treatment approach over the next three months (rated from 1 $=$ unlikely, to $7=$ likely). Seven items assessed respondent attitude (useful-useless; beneficial-harmful; good practice-bad practice; helpful-unhelpful; the right thing to do-the wrong thing to do; and appropriate-inappropriate). The positive anchor was positioned to the left (i.e. rated ' 1 ') and to the right (i.e. rated ' 7 ') on alternating items as recommended. ${ }^{25} \mathrm{~A}$ further two items assessed respondent subjective norm (i.e. felt social pressure: one item concerning colleagues from other professions, and another item colleagues from one's own profession). Finally, four items assessed perceived behavioral control of the decision to provide non-pharmacological approaches for PSE (i.e. sense of control: two items relating to confidence and two items to freedom to act). Respondents provided their sex, professional background, the setting in which they worked (acute, post-acute or combined acute and postacute) and length of time working in stroke care.

\section{Contacting Respondents}

At the time of our survey 10 of the $14 \mathrm{HBs}$ in Scotland, UK had organised multidisciplinary inpatient stroke unit care, each with a Managed Service Network (MSN) stroke coordinator. The stroke coordinator in each HB contact was approached to obtain the named clinical professional lead for each of the six groups the questionnaire was to be distributed to, namely medicine, nursing, physiotherapy, occupational therapy, speech therapy and clinical psychology. These professional leads were contacted by telephone and agreement was reached for them to disseminate an email link to an online version of the survey. The Survey Monkey 
platform was used (www.surveymonkey.com). Paper copies of the questionnaire were distributed when staff might not have computer access. Respondents could post paper copies of the questionnaire (anonymously) to the lead researcher.

\section{Sample Demographics}

A total of 220 individuals completed questionnaires (207 online, 13 returned by post). Respondent details are shown in Table 2. The majority were female and most were experienced professionals (69\% had worked in stroke care settings for 6 or more years). Approximately equal numbers were from nursing, speech therapy, occupational therapy and physiotherapy, with smaller proportions from medicine and clinical psychology. A quarter worked in acute stroke care and three quarters either in post-acute or combined acute and post-acute settings.

We invited a proportion (10\%) of the respondents to complete the survey questionnaire on a second occasion, two weeks after the first. We did this to determine the stability of the intention (to provide non-pharmacological PSE treatments) construct.

\section{Ethical Considerations}

Local Research Ethics Committee (LREC) approval was sought. Full LREC review was not required because the project was determined to be an opinion survey seeking the views of clinical staff on service delivery. Instead, written signed Research and Development (R\&D) management approval was obtained from each of the $10 \mathrm{HBs}$ that took part in the research. Because all responses were completed anonymously, 
written consent was not requested from participants; consent was assumed to have been provided on completion of the questionnaire. Data were not analysed per HB so that neither respondents nor any stroke unit were identifiable. This manuscript conforms to the STROBE Guidelines. ${ }^{38}$

INSERT TABLE 1 HERE

\section{Results}

List of Non-Pharmacological PSE Interventions

Table 2 shows the non-pharmacological interventions for PSE that were identified as well as the source of each one. The total number was 17 . The largest number $(n=12)$ were identified from the focus groups; of these, 7 were mentioned by no other source. In actual fact, 11 of the 17 approaches (65\%) were single source suggestions.

INSERT TABLE 2 HERE

The interventions were grouped into three intervention categories: provision of written/verbal information $(n=3)$; situation-specific approaches (i.e. undertaken by a therapist when PSE occurs; $n=7$ ); and general training approaches (i.e. undertaken by the patient following specific training/instruction; $n=7$ ) (see Table 1 ). 
Determining the Stability of Intention

Twenty-two respondents were re-administered the survey questionnaire two weeks after initial completion ( 6 physiotherapy, 5 speech therapy, 4 nursing, 3 occupational therapy, 2 clinical psychology and 1 medicine; 77\% had worked in stroke care for 6 years or more). The Spearman rank order correlation between ratings at both time points was $r=0.78, p<0.001$ indicating good stability within individuals over time.

The Non-Pharmacological Approaches Used by Clinicians

Respondents' ratings of the frequency with which they use each strategy and their judgements about each strategy's perceived usefulness are shown in Table 3. Thirteen approaches had median scores at or above the mid-point on the frequency scale, and the remainder below. In contrast, all bar one approach (instruct how to tense facial muscles) was rated at the mid-point or above in terms of perceived effectiveness. Spearman rank order correlations between frequency of use and perceived effectiveness ranged from 0.37 to 0.70 ( $p<0.001$ in all cases).

INSERT TABLE 3 HERE 
Predicting Intention to use Non-Pharmacological Approaches

Descriptive statistics for the Theory of Planned Behavior variables are shown in Table 4. To aid comparison, deviation scores were calculated as +0.39 for behavioral intention, -0.20 for attitude, +0.17 for subjective norm, -0.27 for perceived control, based on the mean deviation from the 0-7 scale mid-point of each item (in the case of intention) or scale (in the case of attitude, subjective norm and perceived control), as in a previous TPB study in stroke. ${ }^{29}$ The deviation score for attitude sits just below the notional mid-point, indicating that respondents were not particularly positive in their overall attitude to using non-pharmacological approaches. All professional groups however indicated intention to such an approach at the upper end of the scale (clinical psychologists highest, speech therapists lowest - though between group differences were small; see Table 4).

INSERT TABLE 4 HERE

Table 5 provides the results of an ordered logistic regression analysis predicting respondent intention to provide a non-pharmacological approach for PSE. Responses were averaged for each TPB component. The model had good fit (chi-square $=35.22$ with $3 \mathrm{df}, \mathrm{p}<0.001)$ and indicates that intention tends to increase with more favourable attitude and higher perceived social pressure, but is little associated with perceived control. Together these variables explained $15 \%$ of the variance in intention $\left(R^{2}=0.051\right)$. 


\section{Discussion}

In this paper we report the findings from a national survey of stroke professional practice in relation to PSE, a common and often disabling consequence of stroke. We employed a systematic method to create a comprehensive list of nonpharmacological approaches for PSE as a first step because it had not been clear what the core non-pharmacological techniques and treatments actually were, such is the dearth of research into treatments for PSE, non-pharmacological or otherwise. Certainly published clinical guidelines, a main source of reference for clinical professionals, offered little information: only 3 of the 17 approaches we identified ('distraction', 'educate patients' and 'educate family') were included in the guidelines we consulted, the remaining approaches suggested by textbooks, a stroke training website, or from the clinical intuition of the stroke professionals who took part in our focus groups. For this reason we had neither preconceptions about the approaches used most commonly, nor the ones rated most clinically useful. To address these uncertainties, participants completed a survey questionnaire. We also sought to determine the factors that influence whether stroke professionals offer non-pharmacological approaches, drawing on the Theory of Planned Behavior (TPB) ${ }^{24}$ which has been used to understand the factors underlying professional practice in screening for post-stroke depression ${ }^{29}$ and providing oral hygiene care to stroke patients ${ }^{28}$. Our sample comprised an experienced group of professionals. 
We found strong positive correlations between frequency of use and subjective ratings of effectiveness such that those approaches perceived as most effective were reported to be used most often. The stroke clinicians in our survey reported relatively frequent use of non-pharmacological interventions for PSE. Thirteen of the 17 approaches had median scores at or above the mid-point of our frequency of use rating. Specifically, all three of the 'provision of information' approaches, six of the seven 'situation specific' approaches, and four of the seven 'general training approaches' were rated at the upper end of the frequency scale. Interestingly, the approaches that were referred to by all four information sources we considered 'educate patient' and 'educate family' -received the highest perceived effectiveness ratings. It was less common for the professionals we surveyed to teach patients distraction techniques such as finger tapping or mental imagery, or for them to instruct PSE sufferers in how to tense facial muscles to control symptoms. This is perhaps not surprising given that there do not appear to be any published controlled trials attesting to the efficacy of these approaches, although it is worth noting that the teaching of distraction methods was recommended by both a leading stroke textbook ${ }^{36}$ and also a well-known online stroke training resource. ${ }^{37}$

Most respondents reported high intention to provide non-pharmacological approaches, and the intention to do so appears to be a relatively stable construct. Perhaps unsurprisingly, it was clinical psychologists who expressed strongest intention amongst those surveyed, but the differences between professional groups were modest. Regression analysis indicated that the two TPB variables that 
predicted intention were subjective norm and attitude. Specifically, respondents who perceived others to hold them professionally responsible for carrying out nonpharmacological approaches were most likely to use them, as were respondents who held more positive attitudes. In previous research, social pressure has been shown to be a key factor in the intention of nurses and therapists to use clinical practice guidelines with attitudes, as in our study, playing a smaller, though still important role. ${ }^{39}$ The amount of perceived control professionals perceived themselves to have over the decision to provide a non-pharmacological treatment approach for PSE did not appear to be related to intention, either in univariate or multivariate analyses.

As already pointed out, there is a lack of evidence about the effectiveness of nonpharmacological approaches for PSE. Of course, absence of evidence does not mean evidence of absence; there is a need for research to evaluate whether the approaches included in our survey questionnaire are clinically effective - alone or in combination with antidepressant medication - as well as acceptable to patients. This need is especially pressing because our survey suggests that professionals regularly offer treatments that have, at best, anecdotal evidence of effectiveness. Situation specific approaches may be difficult to evaluate (for example the directive to 'offer reassurance' is surely a natural part of clinical practice and not an action that would ever be withheld), but the impact of information, whether in the form of face-to-face discussion with stroke survivors or via information leaflets is relatively easy to evaluate in a controlled trial, ${ }^{40}$ and certainly relaxation approaches have been evaluated in the treatment of acquired language problems ${ }^{41}$ and anxiety disorders ${ }^{42}$ following stroke. There is, however, a need for researchers to be clear 
about what is meant by a technique or treatment. To take an example, 'normalize the condition' could involve giving information about prevalence of PSE (if an individual believed the condition was very rare), or explaining that PSE occurs as a result of stroke damage rather than personal weakness (if an individual was selfblaming), or some other procedure.

If particular non-pharmacological treatments are found to be effective in future trials, then our findings shed light on the factors that influence intention to use them. It is important such factors are taken into account because of the wellestablished barriers to the translation of research evidence into routine clinical care. Feelings of subjective control and freedom to act were not related to intention. This could be because most of the non-pharmacological approaches included in our survey questionnaire do not require special equipment, or special training, as indicated by the fact that all six professional groups reported similar intention to offer them. The most important factor that emerged from our TPB analysis was subjective norm, that is to say the expectation - explicit or implicit - that the professional should offer non-pharmacological approaches: those who did not believe others expected them to provide non-pharmacological approaches indicated low intention to do so. Clinical guidelines would be a good way to specify the most appropriate interventions and who should provide them, as would professional training courses. In addition, those holding positive attitudes had higher intention ratings, but overall attitudes were mildly negative towards non-pharmacological approaches. This may, of course, be a simple reflection of the lack of published research evidence promoting alternatives to medication treatment. It goes without 
saying that stroke professionals must always question the choices they make about treatments which do not currently have any evidence to support them, not least because clinical resources in stroke settings are often stretched quite thinly. ${ }^{11}$

There are limitations to the study. We gathered data only from stroke care professionals working in inpatient settings. It is difficult therefore to be sure about the generalisability of our data to, for example, community stroke practitioners. This is an issue future work must address, given both the prevalence data that PSE persists for up to 1 in 8 stroke survivors in the longer term, ${ }^{6}$ and because most stroke survivors reside in the community, not hospital ward settings. That said, the bulk of stroke care is still delivered within in-patients stroke settings, where this survey evaluation took place. Relatedly, we have no data about the use of pharmacological treatments for PSE in the inpatient units we surveyed. This may have varied from unit to unit. The extent to which stroke clinicians favoured pharmacological approaches may have influenced their stated intention to provide nonpharmacological approaches either instead of, or alongside medication.

Also, although we obtained responses from 220 individuals it is difficult to know exactly how representative of the wider stroke workforce our data are. However, previous similar research ${ }^{17}$ had a lower number of respondents than the current study, and we did obtain data from all the main stroke health care disciplines, including clinical psychology. Related to this, as the survey explored usual practices in UK (European, Western) stroke settings, the evaluation is open to the criticism of being rather culture-specific. It is not known whether there would be response 
differences in other parts of the world, e.g. Asia, North or South America thus data generalizability could again be questioned. We did not search electronic databases for published work on non-pharmacological approaches for emotionalism, although all of the stroke guidelines we consulted had used well defined literature search methods. Finally, as this was an anonymized, electronic survey, we did not collect individual (named) health professional responses and thus we cannot report the overall questionnaire return rates.

As a final consideration, almost half of the interventions used by study participants received no mention in the clinical guidelines and stroke textbooks we consulted. And so, there is a need for research to determine if the approaches we now know to be used in stroke care are actually clinically effective. Our survey data are useful for investigators deciding the non-pharmacological PSE approaches to put to the test, and indicate the factors that influence their use in clinical practice.

\section{Acknowledgements}

Text removed to allow blind review.

\section{Disclosure statement}

The authors declared no potential conflicts of interest with respect to the research, authorship and/or publication of this article.

\section{Funding}

Text removed to allow blind review. 


\section{References}

1. House AO, Dennis M, Molyneux A, et al. Emotionalism after stroke. Br Med J. 1989; 298: 991-994.

2. Feinstein A, Feinstein K, Gray T, et al. Prevalence and neurobehavioral correlates of pathological laughing and crying in multiple sclerosis. Arch Neurol. 1997; 54: $1116-1121$.

3. Petracca GM, Jorge RE, Acion L, et al. Frequency and correlates of involuntary emotional expression disorder in Parkinson's disease. J Neuropsychiatry Clin Neurosci. 2009; 21: 406-412.

4. Thakore NJ and Pioro EP. Laughter, crying and sadness in ALS. J Neurol Neurosurg Psychiatry. 2017; 88: 825-31.

5. Allida S, Patel K, House A, et al. Pharmaceutical interventions for emotionalism after stroke. Cochrane Database Syst Rev 2019; Issue 3: Art No.: CD003690. DOI: 10.1002/14651858.CD003690.pub4.

6. Gillespie DC, Cadden AP, Lees R, et al. Prevalence of pseudobulbar affect following stroke: A systematic review and meta-analysis. J Stroke Cerebrovasc Dis. 2016; 25: 688-694. 
7. Parvizi J, Anderson SW, Martin CO, et al. Pathological laughter and crying: a link to the cerebellum. Brain. 2001; 124: 1708-1719.

8. Cummings JL, Arciniegas DB, Brooks BR, et al. Defining and diagnosing involuntary emotional expression disorder. CNS Spectr. 2006; 11: 1-7.

9. Ahmed A, Simmons Z. Pseudobulbar affect: prevalence and management. Ther Clin Risk Manag. 2013; 1: 483-489.

10. Calvert T, Knapp P and House A. Psychological associations with emotionalism after stroke. J Neurol Neurosurg Psychiatry. 1998; 65: 928-929.

11. McAleese N, Guzman A, O'Rourke S, et al. (in press) Post-stroke emotionalism: a qualitative investigation. Disabil Rehabil.

12. Allman P, Hope A and Fairburn C. Crying following stroke: A report on 30 cases. Gen Hosp Psychiatry. 1992; 14: 315-321.

13. Tang WK, Chan SS, Chiu HF, et al. Emotional incontinence in Chinese stroke patients: Diagnosis, frequency, and clinical and radiological correlates. J Neurol. 2004; 251: 865-869.

14. Kim JS, Choi-Kwon S. Poststroke depression and emotional incontinence: Correlation with lesion location. Neurology. 2000; 54: 1805-1810. 
15. Kim JS. Pathologic laughter after unilateral stroke. J Neurol Sci. 1997; 148: 121125.

16. Intercollegiate Stroke Working Party. National Clinical Guideline for Stroke. 5th ed. London: Royal College of Physicians; 2016.

17. Jones F and Riazi A. Self-efficacy and self-management after stroke: A systematic review. Disabil Rehabil. 2011; 33: 797-810.

18. Sacco S, Sara M, Pistoia F, et al. Management of pathologic laughter and crying in patients with locked-in syndrome: A report of four cases. Arch Phys Med Rehabil. 2008; 89: 775-778.

19. Kasprisin A. Alternative cognitive therapy for emotional instability (pathologic laughing and crying). Phys Med Rehabil Clin North America. 2004; 15: 883-917.

20. Perotti LP, Cummings LD, Mercado J. Behavioral treatment of pseudobulbar affect: a case report. Perspect Psychiatr Care. 2016; 52: 82-87.

21. Kneebone, II. A framework to support cognitive behaviour therapy for emotional disorder after stroke. Cogn Behav Pract. 2016; 23: 99-109. 
22. Kangas M, McDonald S. Is it time to act? The potential of acceptance and commitment therapy for psychological problems following acquired brain injury. Neuropsychol Rehabil. 2011; 21: 250-276.

23. Picton H. Post-stroke depression (PSD) and post-stroke emotional lability (PSEL): a systematic review of non-pharmacological interventions for PSD and a qualitative study of specialist professionals' conceptualisation of PSEL. 2014. Edinburgh Research Archive. https://www.era.lib.ac.uk/handle/1842/97 (accessed 22 July 2019).

24. Ajzen, I. Attitudes Personality and Behaviour. Milton Keynes: OUP; 1988.

25. Francis JJ, Eccles MP, Johnston M, et al. Constructing questionnaires based on theory of planned behaviour: A manual for health service researchers. Newcastle upon Tyne: Centre for Health Services Research; 2004.

26. Nelson JM, Cook PF, Ingram JC. Utility of the theory of planned behavior to predict nursing staff blood pressure monitoring behaviours. J Clin Nurs. 2014; 23: 461-470.

27. Knowles S, Lawrence LT, Mclnnes E, et al. Knowledge, attitudes, beliefs and behaviour intentions for three bowel management practices in intensive care: effects of a targeted protocol implementation for nursing and medical staff. $B M C$ Nurs. 2015: 14:6 DOI 10.1186/s12912-015-0056-z. 
28. Malik NA, Yatim SM, Lam OLT, et al. Factors influencing the provision of oral hygiene care following stroke: an application of the Theory of Planned Behaviour. Disabil Rehabil. 2018; 40: 889-893.

29. Hart S, Morris R. Screening for depression after stroke: an exploration of professionals' compliance with guidelines. Clin Rehabil. 2008; 22: 60-70.

30. Eccles MP, Hrisos S, Francis J, et al. Do self-reported intentions predict clinicians' behaviour: a systematic review. Implement Sci. 2006; 1:28.

31. Mohr JP, Wolf PA, Grotta JC, et al. Stroke: Pathophysiology, Diagnosis, and Management. Philadelphia, PA: Saunders Elsevier; 2011.

32. Caplan LR (Ed). Caplan's Stroke: A Clinical Approach (4th Ed). Philadelphia, PA: Saunders Elsevier; 2009.

33. Brainin M, Heiss WD (Eds). Textbook of Stroke Medicine. Cambridge, UK: Cambridge University Press; 2010.

34. Robinson, RG. Stroke Recovery and Rehabilitation: Cognitive, Behavioral and Emotional Disorders Following Vascular Brain Injury. Cambridge, UK: Cambridge University Press; 2006. 
35. Stein J, Harvey R, Macko R, et al (Eds). Stroke Recovery and Rehabilitation. New York, NY: Demos Medical Publishing; 2009.

36. Lincoln NB, Kneebone II, Macniven JAB, et al. Psychological Management of Stroke. Chichester, UK: Wiley-Blackwell; 2012.

37. Chest Heart and Stroke Scotland Stroke Training and Awareness Resources (STARs), www.strokeadvancingmodules.org (2015, accessed 22 July 2019).

38. von Elm E, Altman DG, Egger M, et al. The Strengthening the Reporting of Observational Studies in Epidemiology (STROBE) statement: guidelines for reporting observational studies. Lancet. 2007; 370: 1453-1457.

39. Kortteisto T, Kaila M, Komulainen J, et al. Healthcare professionals' intentions to use clinical guidelines: a survey using the theory of planned behaviour. Implement Sci. 2010; 5: 51.

40. Mant J, Carter J, Wade DT, et al. The impact of an information pack on patients with stroke and their carers: a randomized controlled trial. Clin Rehabil. 1998; 12: 465-476.

41. Murray LL and Ray AH. A comparison of relaxation training and syntax stimulation for chronic nonfluent aphasia. J Commun Disord. 2001; 34: 87-113. 
42. Golding K, Fife-Schaw C and Kneebone I. Twelve month follow-up on a randomized controlled trial of relaxation training for post-stroke anxiety. Clin Rehabil. 2017; 31: 1164-1167.

Table 1. Sample participant details

\begin{tabular}{|l|c|c|}
\hline & N & \% \\
\hline Staff group & & \\
Nursing & 54 & $25 \%$ \\
Speech Therapy & 45 & $20 \%$ \\
Occupational Therapy & 45 & $20 \%$ \\
Physiotherapy & 42 & $19 \%$ \\
Medicine & 21 & $10 \%$ \\
Clinical Psychology & 13 & $6 \%$ \\
\hline Sex & & \\
Male & 34 & $16 \%$ \\
Female & 186 & $84 \%$ \\
\hline Stroke setting & & \\
Acute & 55 & $25 \%$ \\
Post-acute & 88 & $40 \%$ \\
\hline
\end{tabular}




\begin{tabular}{|l|l|l|}
\hline Combined & 75 & $34 \%$ \\
\hline Time in stroke care & & \\
0-2yrs & 33 & $15 \%$ \\
3-5yrs & 36 & $16 \%$ \\
6-10yrs & 52 & $24 \%$ \\
$>11$ yrs & 98 & $45 \%$ \\
\hline
\end{tabular}

Table 2. Non-pharmacological approaches for PSE (including sources)

\begin{tabular}{|l|l|}
\hline Non-pharmacological treatment approach & $\begin{array}{l}\text { Source of } \\
\text { recommendation }\end{array}$ \\
\hline Provision of information & \\
\hline 1. Provide education for patient & (a) (b) (c) (d) \\
\hline 2. Provide education for family & (a) (b) (c) (d) \\
\hline 3. Normalize the condition & (d) \\
\hline & \\
\hline Situation-specific approaches (undertaken by therapist when PSE occurs) & \\
\hline 4. Distract the patient & (a) (c) (d) \\
\hline 5. Acknowledge the PSE then continue with current activity & (c) (d) \\
\hline 6. Suggest altered body posture (e.g. shoulders back instead of slouched) & (c) \\
\hline 7. Ignore the PSE and continue with current activity & (d) \\
\hline 8. Offer reassurance & (d) \\
\hline 9. Move the patient to another setting/location & (d) \\
\hline
\end{tabular}




\begin{tabular}{|l|l|}
\hline 10. Ask the patient to take a deep breath & (d) \\
\hline & \\
\hline General training approaches (i.e. undertaken by patient following training) & \\
\hline 11. Teach relaxation techniques (e.g. deep breathing) & (b) (c) (d) \\
\hline 12. Teach distraction techniques (e.g. finger tapping; mental imagery) & (b) (c) \\
\hline 13. Instruct how to tense facial muscles & (b) \\
\hline 14. Modify the patient's beliefs about PSE (i.e. thought challenge) & (b) \\
\hline 15. Encourage the patient to use a diary to record feelings & (c) \\
\hline 16. Identify the triggers for PSE (so they can be avoided) & (d) \\
\hline 17. Talk to the patient about their goals & (d) \\
\hline
\end{tabular}

Key: Approaches identified from (a) published stroke guidelines; (b) stroke textbooks; (c) STARS website; (d) focus groups - see Methods for explanation 
Table 3. Frequency of use and perceived effectiveness of non-pharmacological treatment approaches for PSE

\begin{tabular}{|c|c|c|c|c|c|}
\hline \multirow[b]{2}{*}{ Non-pharmacological treatment approach } & \multicolumn{2}{|c|}{ Frequency of use $^{\dagger}$} & \multicolumn{2}{|c|}{$\begin{array}{c}\text { Perceived } \\
\text { effectiveness }^{\dagger}\end{array}$} & \multirow{2}{*}{$\begin{array}{c}\text { Correlation } \\
r\end{array}$} \\
\hline & Median & IQR & Median & IQR & \\
\hline Offer reassurance & 5 & {$[4,6]$} & 5 & {$[4,6]$} & $0.37^{*}$ \\
\hline Talk to the patient about their goals & 5 & {$[4,6]$} & 5 & {$[4,6]$} & $0.44^{*}$ \\
\hline $\begin{array}{l}\text { Acknowledge the PSE then continue with current } \\
\text { activity }\end{array}$ & 5 & {$[4,6]$} & 5 & {$[4,6]$} & $0.51^{*}$ \\
\hline Provide education for patient & 5 & {$[3,5]$} & 5 & {$[4,6]$} & $0.58^{*}$ \\
\hline Provide education for family & 4 & {$[3,5]$} & 5 & {$[4,6]$} & $0.56 *$ \\
\hline Normalize the condition & 4 & {$[3,5]$} & 4 & {$[3,5]$} & $0.49 *$ \\
\hline Distract the patient & 4 & {$[3,5]$} & 5 & {$[4,5]$} & $0.48^{*}$ \\
\hline Ask the patient to take a deep breath & 4 & {$[3,5]$} & 4 & {$[3,6]$} & $0.56^{*}$ \\
\hline $\begin{array}{l}\text { Identify the triggers for PSE (so they can be } \\
\text { avoided) }\end{array}$ & 4 & {$[2,5]$} & 4 & {$[3,5]$} & $0.61 *$ \\
\hline Teach relaxation techniques (e.g. deep breathing) & 4 & {$[3,5]$} & 5 & {$[3,6]$} & $0.45^{*}$ \\
\hline Move the patient to another setting/location & 4 & {$[3,5]$} & 4 & {$[3,5]$} & $0.63^{*}$ \\
\hline $\begin{array}{l}\text { Suggest altered body posture (e.g. shoulders back } \\
\text { instead of slouched) }\end{array}$ & 4 & {$[3,5]$} & 4 & {$[3,5]$} & $0.70^{*}$ \\
\hline $\begin{array}{l}\text { Modify the patient's beliefs about PSE (i.e. thought } \\
\text { challenge) }\end{array}$ & 4 & {$[2,5]$} & 4 & {$[3,5]$} & $0.59 *$ \\
\hline Ignore the PSE and continue with current activity & 3 & {$[2,4]$} & 4 & {$[2,4]$} & $0.48^{*}$ \\
\hline $\begin{array}{l}\text { Encourage the patient to use a diary to record } \\
\text { feelings }\end{array}$ & 3 & {$[2,4]$} & 4 & {$[2,5]$} & $0.69 *$ \\
\hline $\begin{array}{l}\text { Teach distraction techniques (e.g. finger tapping; } \\
\text { mental imagery) }\end{array}$ & 3 & {$[2,5]$} & 4 & {$[3,5]$} & $0.69 *$ \\
\hline Instruct how to tense facial muscles & 3 & {$[2,4]$} & 3 & {$[2,4]$} & $0.57^{*}$ \\
\hline
\end{tabular}

Key: ${ }^{+}$ratings from 1 to 7 , higher scores indicating most often and higher perceived effectiveness

* correlation $\mathrm{p}<0.001$ (2-tailed)

$\mathrm{IQR}=$ interquartile range 
Table 4. Descriptive statistics for Theory of Planned Behavior variables

\begin{tabular}{|l|c|c|c|}
\hline TPB component & Median & IQR & $\begin{array}{c}\text { Correlation with BI } \\
\text { (Spearman rho) }\end{array}$ \\
\hline Behavioral intention (overall sample) & 5 & {$[3,7]$} & \\
Clinical Psychology & 7 & {$[5,7]$} & \\
Physiotherapy & 6 & {$[4,7]$} & \\
Occupational Therapy & 5 & {$[4,7]$} & \\
Medicine & 5 & {$[3,7]$} & \\
Nursing & 5 & {$[3,7]$} & \\
Speech Therapy & 5 & {$[3,7]$} & \\
\hline Attitude & 24 & {$[22,25]$} & $0.27, \mathrm{p}<0.001$ \\
\hline Subjective norm & 8 & {$[7,10]$} & $0.34, \mathrm{p}<0.001$ \\
\hline Perceived control & 15 & {$[13,17]$} & $-0.06, \mathrm{p}=0.382$ \\
\hline
\end{tabular}


Table 5. Results of ordered logistic regression analysis

\begin{tabular}{|c|c|c|c|c|c|c|}
\hline Variable & Beta & t-value & Significance & Adjusted $\mathbf{R}^{2}$ & Model F & F significance \\
\hline & & & & 0.151 & 12.214 & $<0.001$ \\
\hline $\begin{array}{l}\text { Attitude } \\
\text { Coefficient }=0.14 \\
\text { Wald } Z=2.55 \\
\text { p-value }=0.001\end{array}$ & 0.13 & 2.51 & 0.013 & & & \\
\hline $\begin{array}{l}\text { Subjective norm } \\
\text { Coefficient }=0.22 \\
\text { Wald } Z=4.50 \\
\text { p-value }=<0.001\end{array}$ & 0.12 & 4.64 & $<0.001$ & & & \\
\hline $\begin{array}{l}\text { Perceived control } \\
\text { Coefficient }=-0.02 \\
\text { Wald } Z=-0.58 \\
\text { p-value }=0.562\end{array}$ & -0.04 & -0.92 & 0.360 & & & \\
\hline
\end{tabular}


Figure 1. Theory of Planned Behavior (adapted from Ajzen 1988)

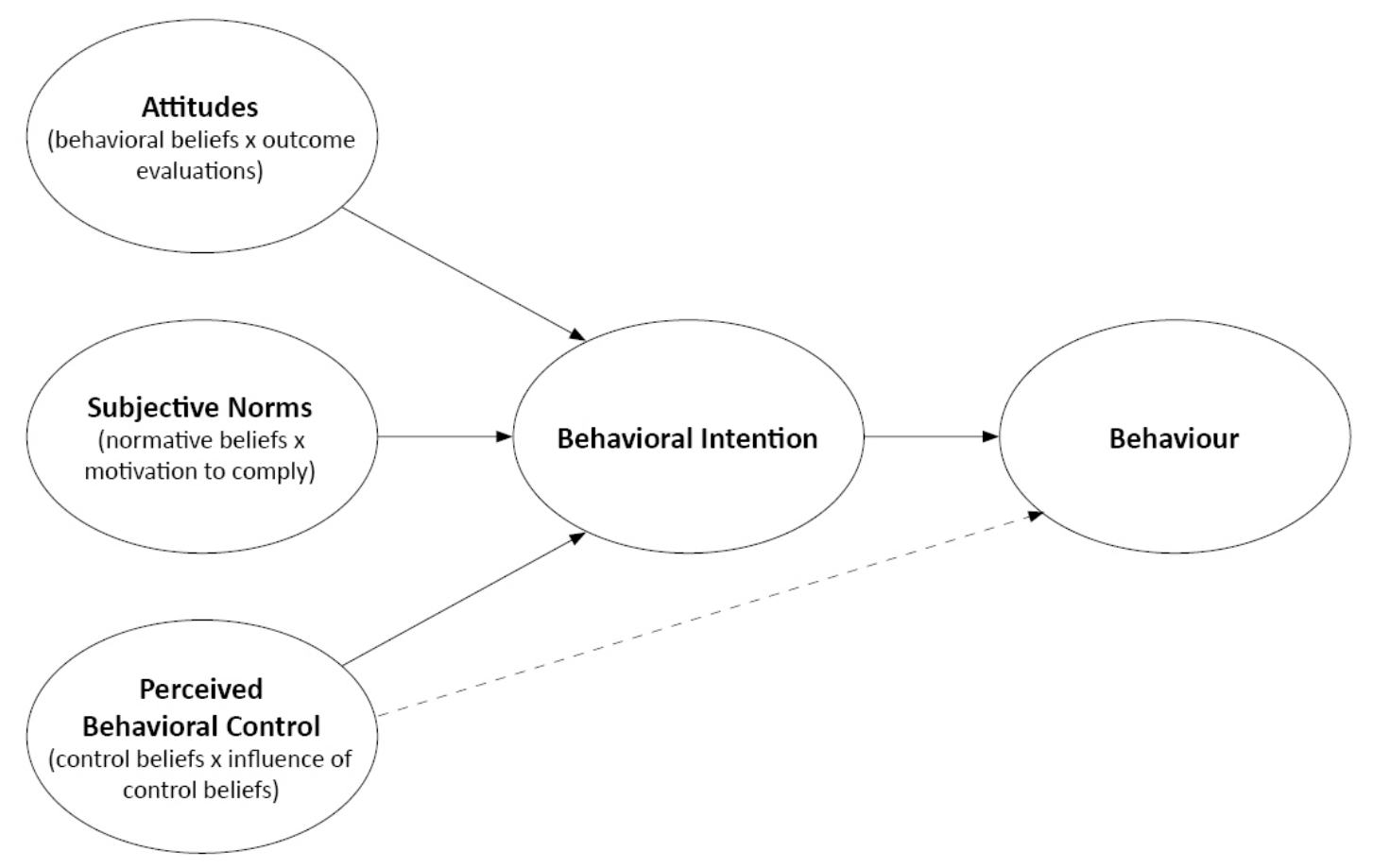


Appendix. PSE survey questionnaire

\section{Background details}

Q1. Location of stroke service: Acute $\square$; Post-acute $\square$; Combined acute/post-acute $\square$

Q2. Gender: Male $\square$; Female $\square$

Q3. Staff group: Medicine $\square$; Nursing $\square$; Occupational Therapy $\square$; Physiotherapy $\square$; Psychology $\square$; Speech Therapy $\square$; Other $\square$ (please state)

Q4. The length of time you have worked in stroke care: 0-2 yrs $\square ; 3-5$ yrs $\square ; 6-10$ yrs $\square ; 11+$ yrs $\square$

Each question in this survey refers to OFFERING A NON-DRUG TREATMENT APPROACH to inpatients with post-stroke emotionalism (PSE). PSE refers to "a lessening of control over emotions leading to a greater tendency to cry or laugh" (SIGN 118 Guideline, 2010).

Q5. Please estimate: (a) how often over the past 12 months you have provided the following non-drug treatment approaches for PSE; and (b) where you gave a rating of 2 or more on the first scale (i.e. you have provided the approach in question), please rate how effective you have personally found each approach in treating PSE.

\begin{tabular}{|c|c|}
\hline 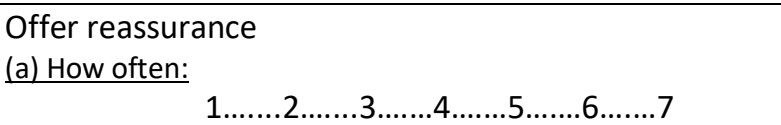 & 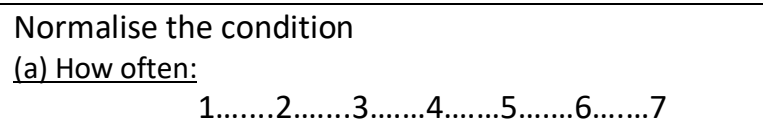 \\
\hline never $\quad$ very often & never $\quad$ very often \\
\hline (b) How effective: & (b) How effective: \\
\hline $1 \ldots \ldots .2 \ldots \ldots . . \ldots \ldots 4 \ldots \ldots . . . \ldots \ldots 6 \ldots . . .7$ & $1 \ldots \ldots .2 \ldots \ldots .3 \ldots \ldots 4 \ldots \ldots .5 \ldots \ldots . \ldots \ldots .7$ \\
\hline very effective & very effective \\
\hline $\begin{array}{l}\text { Encourage the patient to use a diary to record feelings } \\
\text { (a) How often: }\end{array}$ & $\begin{array}{l}\text { Provide education for patient } \\
\text { (a) How often: }\end{array}$ \\
\hline 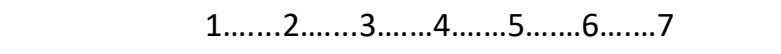 & $1 \ldots \ldots .2 \ldots \ldots .3 \ldots \ldots .4 \ldots \ldots .5 \ldots \ldots .6 \ldots \ldots .7$ \\
\hline very often & very often \\
\hline (b) How effective: & (b) How effective: \\
\hline $1 \ldots \ldots .2 \ldots \ldots .3 \ldots \ldots .4 \ldots \ldots .5 \ldots \ldots . . \ldots \ldots .7$ & $1 \ldots \ldots .2 \ldots \ldots .3 \ldots \ldots .4 \ldots \ldots .5 \ldots \ldots .6 \ldots \ldots 7$ \\
\hline very effective & not effective \\
\hline $\begin{array}{l}\text { Provide education for family } \\
\text { (a) How often: }\end{array}$ & $\begin{array}{l}\text { Instruct how to tense facial muscles } \\
\text { (a) How often: }\end{array}$ \\
\hline 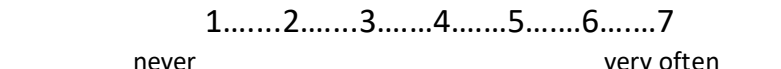 & $1 \ldots \ldots .2 \ldots \ldots .3 \ldots \ldots .4 \ldots \ldots .5 \ldots \ldots . . \ldots \ldots .7$ \\
\hline never & never \\
\hline
\end{tabular}




\begin{tabular}{|c|c|}
\hline 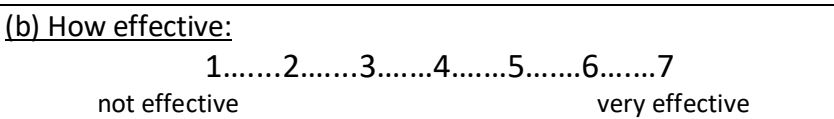 & 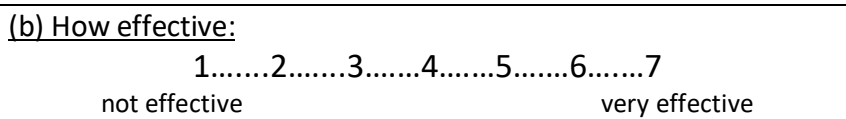 \\
\hline 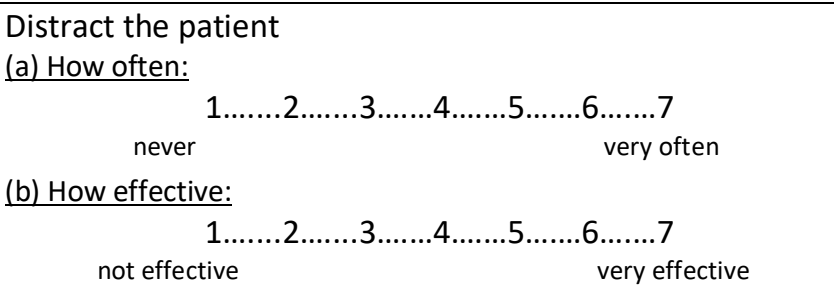 & 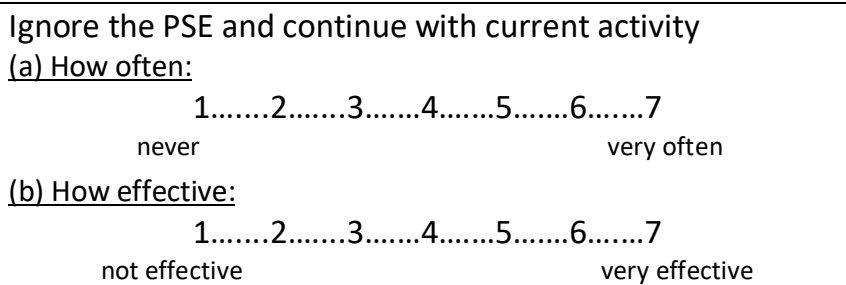 \\
\hline 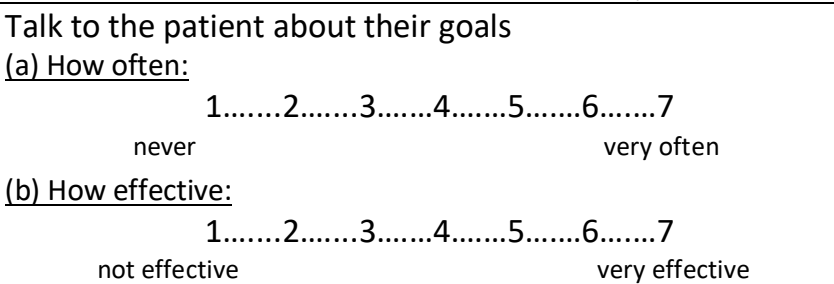 & 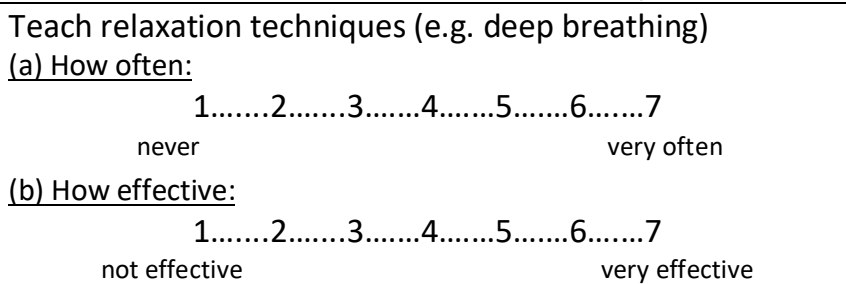 \\
\hline 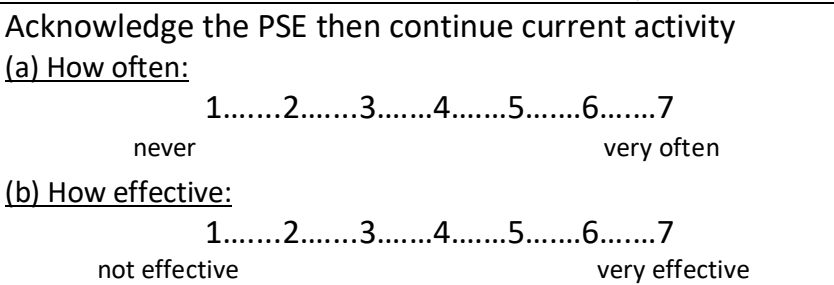 & 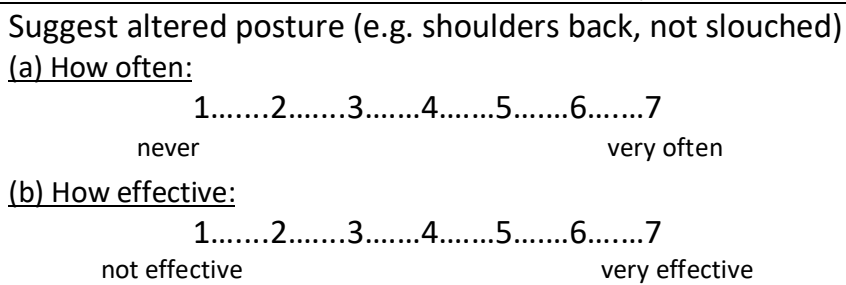 \\
\hline 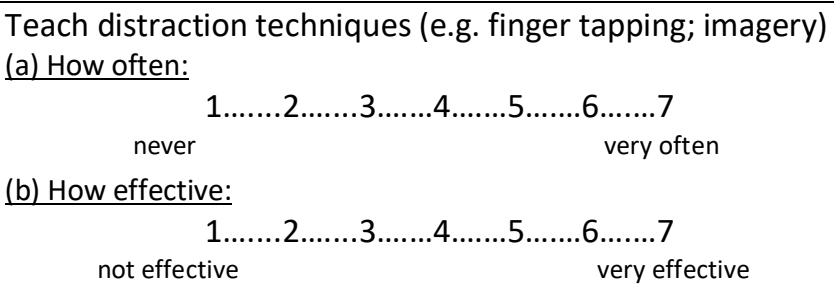 & 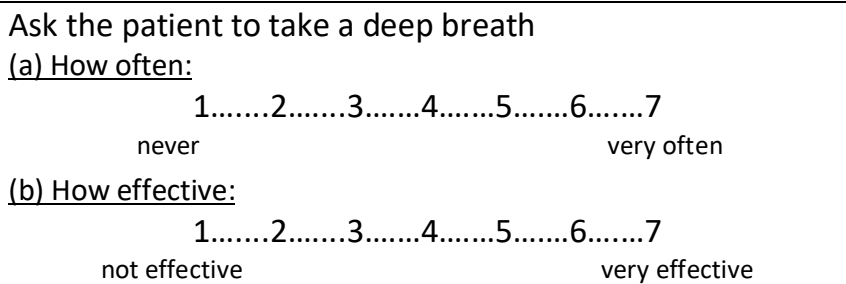 \\
\hline 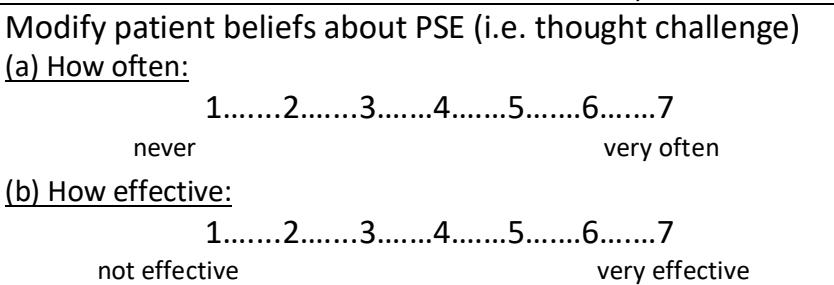 & 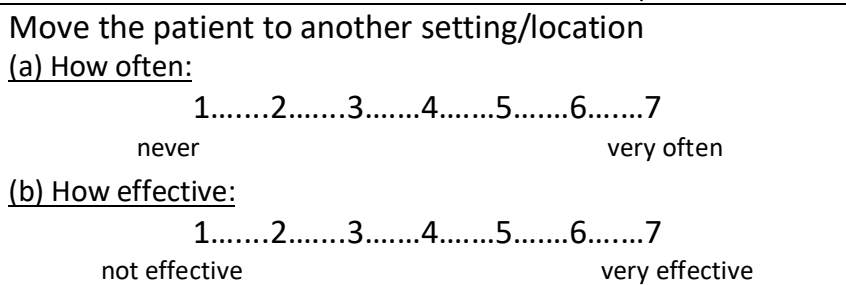 \\
\hline 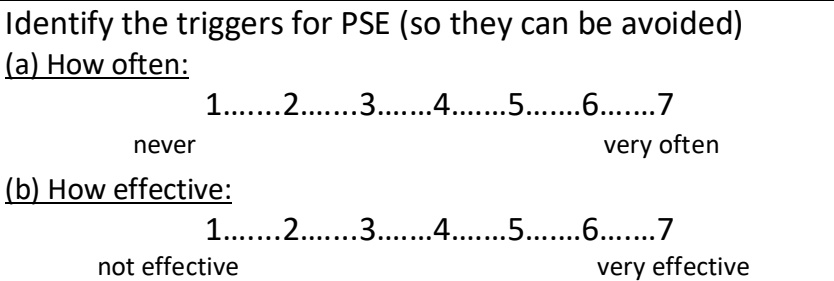 & \\
\hline
\end{tabular}

Q6. On average, how many patients do you see each month with PSE? $\square$

Q7. To distinguish between PSE and post-stroke depression is:

$\begin{array}{lllllllll}\text { Easy } & 1 & 2 & 3 & 4 & 5 & 6 & 7 & \text { Difficult }\end{array}$

Q8. How likely is it that you will provide a non-drug treatment approach for PSE over the next three months?

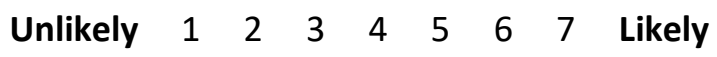

Q9. Non-drug treatment approaches for PSE are:

\begin{tabular}{|r|rrrrrrr|l|}
\hline Useful & 1 & 2 & 3 & 4 & 5 & 6 & 7 & Useless \\
\hline Harmful & 1 & 2 & 3 & 4 & 5 & 6 & 7 & Beneficial \\
\hline
\end{tabular}




\begin{tabular}{|r|rrrrrrr|l|}
\hline Good practice & 1 & 2 & 3 & 4 & 5 & 6 & 7 & Bad practice \\
\hline Unhelpful & 1 & 2 & 3 & 4 & 5 & 6 & 7 & Helpful \\
\hline The right thing to do & 1 & 2 & 3 & 4 & 5 & 6 & 7 & The wrong thing to do \\
\hline Inappropriate & 1 & 2 & 3 & 4 & 5 & 6 & 7 & Appropriate \\
\hline
\end{tabular}

Q10. Colleagues from other professions think I should provide non-drug treatment approaches for PSE

$\begin{array}{lllllllll}\text { Strongly disagree } & 1 & 2 & 3 & 4 & 5 & 6 & 7 & \text { Strongly agree }\end{array}$

Q11. Colleagues from my profession think I should provide non-drug treatment approaches for PSE Strongly disagree $\quad 1 \quad 2 \quad \begin{array}{lllllll} & 1 & 4 & 5 & 6 & 7 & \text { Strongly agree }\end{array}$

Q12. I am confident that I could provide non-drug treatment approaches for PSE if I wanted to Strongly disagree $\quad 1 \quad 2 \quad \begin{array}{lllllll} & 1 & 4 & 5 & 6 & 7 & \text { Strongly agree }\end{array}$

Q13. For me to provide non-drug treatment approaches for PSE is:

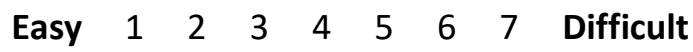

Q14. The decision to provide non-drug treatment approaches for PSE is beyond my control $\begin{array}{llllllllll}\text { Strongly disagree } & 1 & 2 & 3 & 4 & 5 & 6 & 7 & \text { Strongly agree }\end{array}$

Q15. Whether I provide non-drug treatment approaches for PSE or not is entirely up to me $\begin{array}{lllllllll}\text { Strongly disagree } & 1 & 2 & 3 & 4 & 5 & 6 & 7 & \text { Strongly agree }\end{array}$ 